\title{
Transulcal parafascicular minimally invasive approach to deep and subcortical cavernomas: technical note
}

\author{
Robert A. Scranton, MD, ${ }^{1}$ Steve H. Fung, MD, ${ }^{2}$ and Gavin W. Britz, MD, MPH, MBA ${ }^{1}$ \\ Departments of ${ }^{1}$ Neurological Surgery and ${ }^{2}$ Radiology, Houston Methodist Neurological Institute, Houston, Texas
}

Cavernomas comprise $8 \%-15 \%$ of intracranial vascular lesions, usually supratentorial in location and superficial. Cavernomas in the thalamus or subcortical white matter represent a unique challenge for surgeons in trying to identify and then use a safe corridor to access and resect the pathology. Previous authors have described specific open microsurgical corridors based on pathology location, often with technical difficulty and morbidity. This series presents 2 cavernomas that were resected using a minimally invasive approach that is less technically demanding and has a good safety profile. The authors report 2 cases of cavernoma: one in the thalamus and brainstem with multiple hemorrhages and the other in eloquent subcortical white matter. These lesions were resected through a transulcal parafascicular approach with a port-based minimally invasive technique. In this series there was complete resection with no neurological complications. The transulcal parafascicular minimally invasive approach relies on image interpretation and trajectory planning, intraoperative navigation, cortical cannulation and subcortical space access, high-quality optics, and resection as key elements to minimize exposure and retraction and maximize tissue preservation. The authors applied this technique to 2 patients with cavernomas in eloquent locations with excellent outcomes.

http://thejns.org/doi/abs/10.3171/2015.12.JNS152185

KEY WORDS cavernoma; microsurgery; minimally invasive; neural navigation; subcortical surgery; transulcal parafascicular; vascular disorders

$\mathrm{C}$ AVERNOMAS are circumscribed compact masses of dilated, thin-walled sinusoids with variable hyalinization without an arterial feeder. ${ }^{7}$ They are surrounded by hemosiderin-laden macrophages with reactive gliosis and can often be associated with a developmental venous anomaly., ${ }^{4,41}$ Mechanisms of enlargement include reactive gliosis, thrombosis with revascularization, capillary sinusoidal proliferation, neovascularization, and recurrent micro and macro hemorrhages, leading to the release of angiogenic factors to name a few. . $16,30,31,34-37^{-1}$ Presentation is incidental or after mass effect and hemorrhage cause headaches, seizures, sensory symptoms, or focal deficits. ${ }^{11,36,42}$ The estimated incidence is between $0.4 \%$ and $0.9 \% ;{ }^{3}$ cavernomas are usually lobar in location, ${ }^{21,29}$ while deep lesions are found in only $5 \%-17 \%$ of cases. ${ }^{11}$

Open microsurgical corridors to deep cavernomas have been described that vary with the location and follow paths around critical structures or fiber tracts. ${ }^{5,11,21,38}$ Open approaches can be technically demanding, and it is uncertain whether surgical outcomes reported by leaders in the field are comparable to those of their junior colleagues or colleagues at community centers. The present report illustrates the application of a transulcal parafascicular mini- mally invasive approach to access cavernomas in deep or eloquent subcortical white matter with low morbidity and no mortality. This approach evolved from Dr. Kelly's stereotactic tubular dilator and retraction system that he applied to the resection of subcortical and intraventricular brain tumors. ${ }^{15,23}$ The technique has evolved to include the use of real-time intraoperative image guidance and endoscopes with the additional application to colloid cysts and hematoma evacuation. . $^{10,12,14,18,22,25,32,39}$

\section{Surgical Technique Case 1}

This 20-year-old male patient had a 6-month history of acute onset of left-sided hemianesthesia and hemiparesis. The patient had a slow partial recovery and then experienced a rehemorrhage after 4 months with more severe left hemianesthesia, hemiparesis, and proprioceptive deficit, and he ambulated with a sensory ataxic gait. A neurologist diagnosed a right thalamic and brainstem cavernoma and made a neurosurgical referral.

MRI of the brain showed a hemorrhagic mass in the right thalamus extending into the cerebral peduncle and

ABBREVIATIONS DTI = diffusion tensor imaging; $f M R I=$ functional MRI; ICU = intensive care unit; PLIC = posterior limb of the internal capsule.

SUBMITTED September 17, 2015. ACCEPTED December 4, 2015.

INCLUDE WHEN CITING Published online March 4, 2016; DOI: 10.3171/2015.12.JNS152185. 

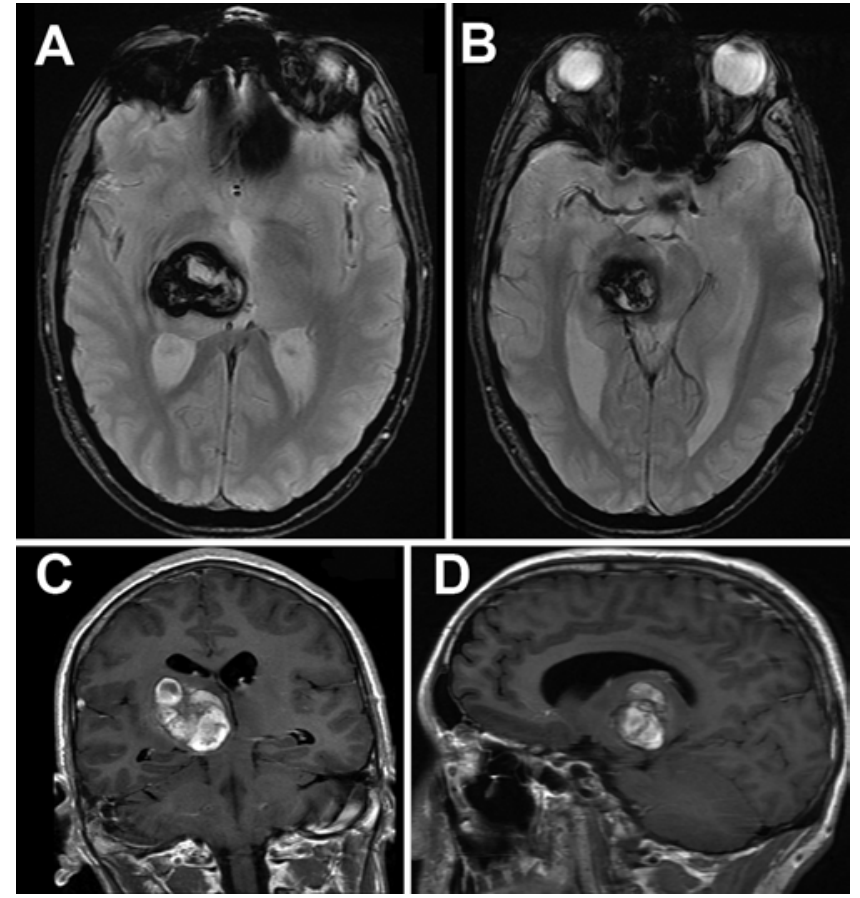

FIG. 1. Case 1. Preoperative axial gradient echo (A and B), coronal T1weighted (C), and sagittal T1-weighted (D) MR images.

midbrain (Fig. 1). Cerebral angiography ruled out vascular abnormality, including developmental venous anomaly. Blood oxygen level-dependent functional MRI (fMRI) and diffusion tensor imaging (DTI) were performed and showed anterior and lateral displacement of the right posterior limb of the internal capsule (PLIC). The right corticospinal tract fibers were identified coursing through the PLIC and being displaced by the cavernoma and hemorrhage cavity (Fig. 2D). The right corticospinal tract wrapped around the lateral surface of the cavernoma and hematoma cavity and began to curve anteriorly; it then took another turn along the inferior border as it approached the cerebral peduncle.

The patient requested surgical management after multiple discussions regarding the natural history and management of cavernomas including observation and resection. Preoperative images were reviewed, and a surgical corridor was designed from an extreme anterior approach through the frontal lobe to reach the cavernoma before the lateral fibers of the corticospoinal tract coursed anterior and inferior around the cavernoma (Fig. 2). The resection was performed 8 weeks after the most recent hemorrhage as an awake craniotomy through a transulcal parafascicular approach with intraoperative navigation. A $4 \times 4-\mathrm{cm}$ right frontal craniotomy was turned prior to awakening the patient, followed by a $14-\mathrm{mm}$ cruciate dural opening. A neurologist was present who monitored the patient's neurological status during the operation. Using the neural navigation, the entry point was identified, a small transulcal entry was made, and the BrainPath (NICO Corp.) was guided to the target. Care was taken to irrigate the external surface of the sheath while guiding it to the target in the subcortical space. The sheath was then secured, and the
A

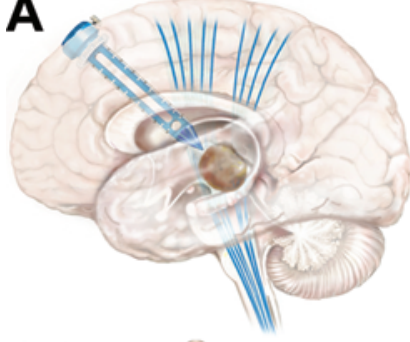

B
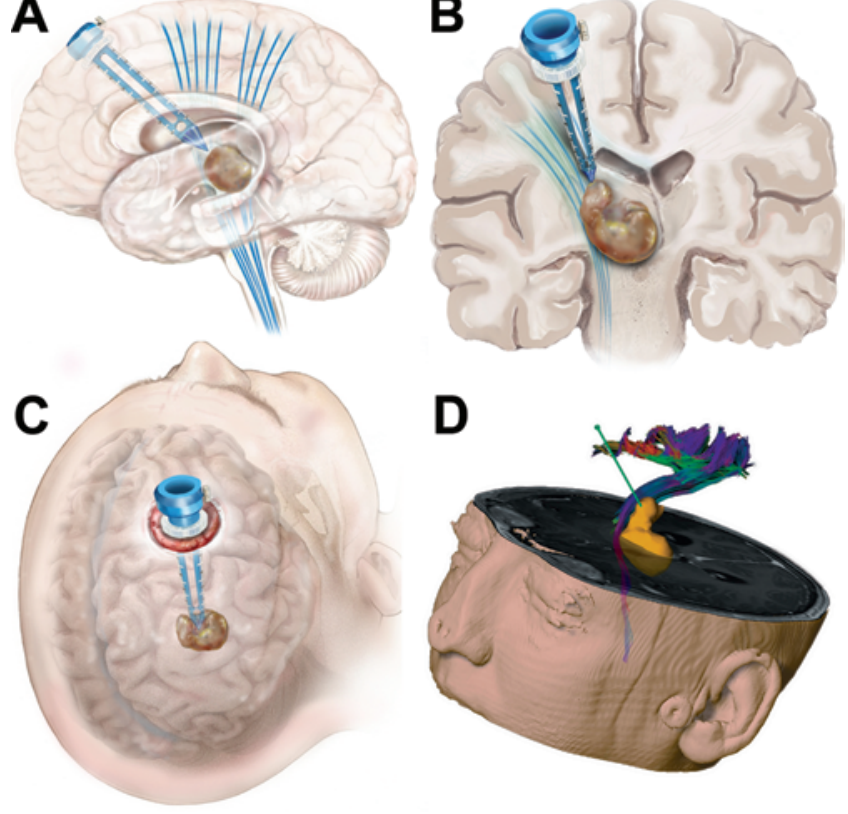

FIG. 2. Case 1. A-C: Artist's illustration of sagittal (A) and coronal planes (B), and the surgeon's view of the approach corridor (C), with the blue lines representing the right corticospinal tract. D: Fusion of the DTI and MRI data. Copyright Houston Methodist Neurosurgery Department. Published with permission.

inner obturator was removed. Visualization was obtained with the aid of an exoscope positioned at a sufficient working distance from the port to allow transit of instruments and was held in place by a robotic arm. The NICO Myriad system (NICO Corp.), suction, and irrigation were used to evacuate the hematoma and resect a vascular abnormality consistent with cavernoma. Hemostasis was obtained with bipolar cautery and irrigation. The sheath was removed slowly a few millimeters at a time to manage any hemorrhaging from the tract. The craniotomy was then closed in standard fashion. No decline in the neurological examination occurred during the procedure. Pathological analysis revealed hemosiderin deposition, granulation tissue, and masses of hyalinized blood vessels with no intervening parenchyma or elastin staining, consistent with cavernoma.

Postoperative examination findings showed improvement in the left hemianesthesia and hemiparesis; the patient was able to ambulate immediately after surgery. The patient spent 1 night in the intesive care unit (ICU), followed by transfer to the floor while waiting for a transfer to rehabilitation. The patient has since been discharged from rehabilitation with significant improvement in his motor deficit and hemianesthesia; he is able to ambulate and run now with only minor difficulty. Two-month postoperative images showed a complete resection (Fig. 3). The patient will continue to be followed with imaging to ensure long-term cure.

\section{Case 2}

This 44-year-old man had undergone resection 20 years previously for a cerebellar medulloblastoma. He had shunt-dependent obstructive hydrocephalus and awoke 

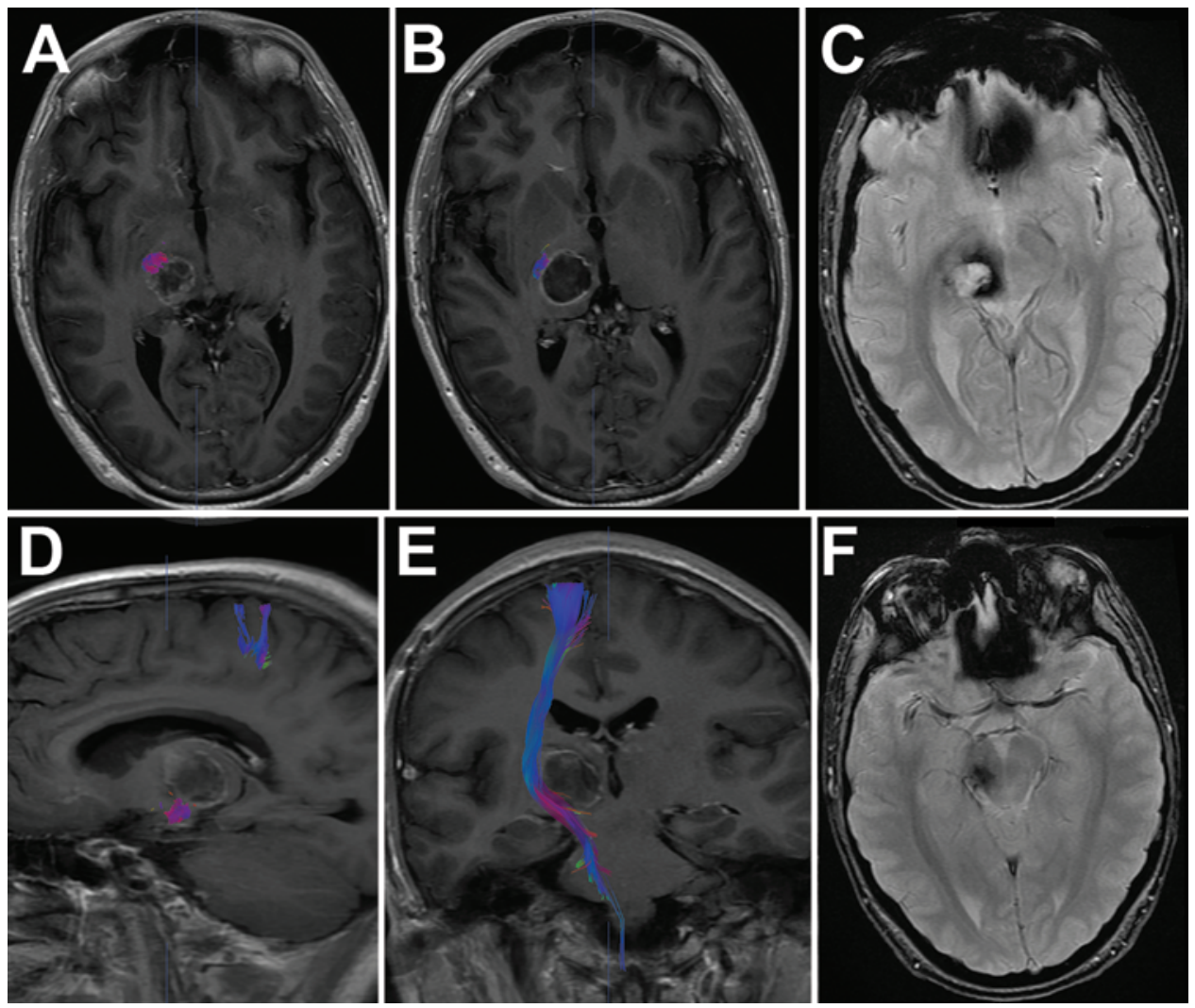

FIG. 3. Case 1. Postoperative T1-weighted MR images with DTI tractography fusion showing the right corticospinal tract in axial (A and $B)$, sagittal (D), and coronal (E) planes. Axial gradient echo sequences showing the depth of the resection (C and F).

with a headache, which led to his current presentation. Examination did not reveal any deficits, such as cognition, motor, sensory, cranial nerve, speech, or gait deficits or evidence of papilledema. The family remarked on occasional speech difficulty. CT scanning showed a $2.4 \times 2.8-$ $\mathrm{cm}$ hyperdense lesion in the right temporal/parietal subcortical white matter. MRI showed an acute hemorrhagic mass with surrounding hemosiderin products and edema consistent with a cavernoma in the subcortical white matter deep to the right superior temporal and supramarginal gyri (Fig. 4). Review of a CT scan from 7 years prior showed a small hyperdensity in this area; unfortunately, all other prior radiographic studies were lost during a natural disaster. Digital subtraction cerebral angiography did not reveal a vascular abnormality. High-resolution MRI with pseudo-continuous arterial spin labeling and DTI was performed, given the eloquent location of the presumed cavernoma and hemorrhage (Fig. 5). The scan revealed possible involvement of the right geniculate nucleus and the right optic radiation including Baum's loop. Meyer's loop was found just inferior to the cavernoma, and the superior longitudinal fasciculus and arcuate fasciculus were found along the superior and posterior aspects of the cavernoma. The right corticospinal tract was approximately 9 $\mathrm{mm}$ anteromedial.

Following a detailed discussion with the patient regarding the nature and natural history of cavernomas, including future observation or surgical management, he requested surgical removal. Resection occurred 4 weeks after the acute episode. The MRI with DTI data were studied, and an entry site was selected at the base of a sulcus. A direct path was taken to the target, ensuring not to disturb the aforementioned tracts (Fig. 5). The procedure was performed in the same manner as in the previous case, but with a posterior right temporal craniotomy. The final pathology was cavernoma.

The patient was transferred to the ICU with stable mild headache but no objective visual, speech, motor, or sensory deficits. He was transferred to the ICU on postoperative Day 1 and was discharged home on postoperative Day 2. One-year follow-up has not revealed any new deficits. The patient's headache has resolved, and there is no cavernoma recurrence on imaging (Fig. 6).

\section{Discussion}

The subcortical space is an eloquent area of the brain that almost entirely comprises important white matter tracts. Surgical access and surgery in this area are dangerous and may result in neurological deficits. Cavernomas are benign lesions; therefore, minimizing surgical injury is even more important. In traditional open surgery, the basic surgical tenants such as minimizing brain retraction and disturbing as little tissue as possible is beneficial.6,11,19,20,28 However, to access this deep space using traditional approaches, the superficial structures and pathways are at 

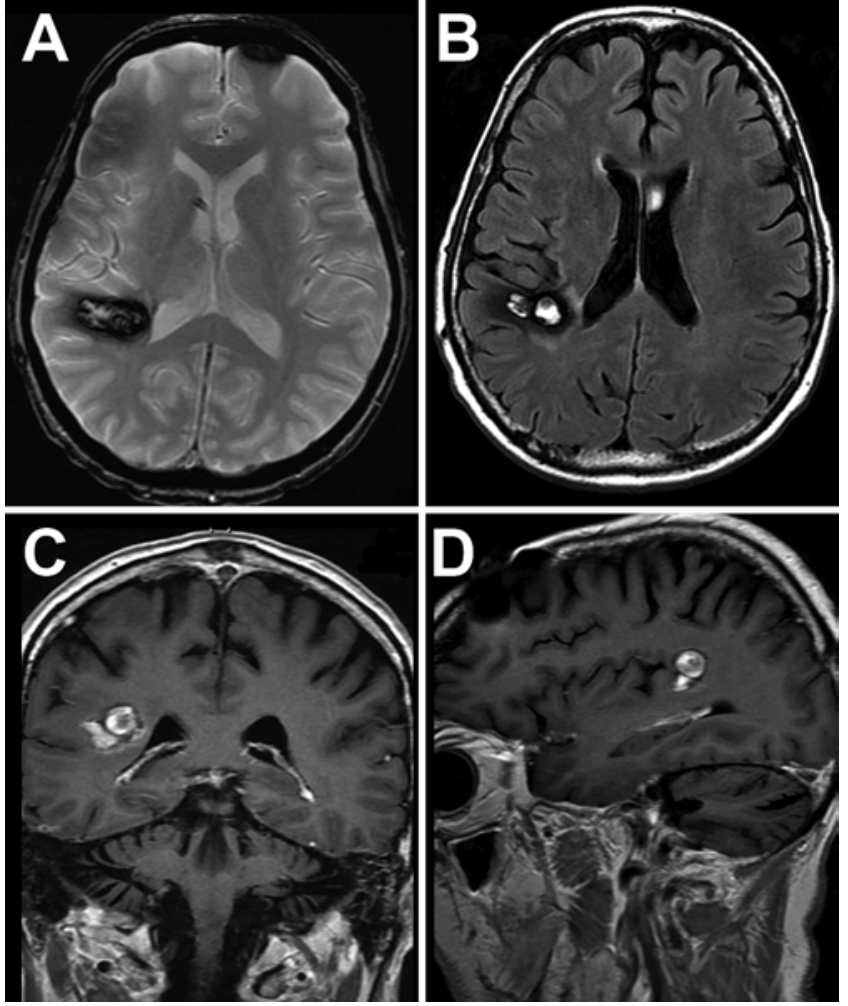

FIG. 4. Case 2. Preoperative MR image with axial gradient echo (A) and T2-weighted FLAIR (B) sequences as well as T1-weighted coronal (C) and sagittal (D) images.

risk. Tissue preservation should be the underlying theme in surgery involving the subcortical space. We report 2 cases in which a transulcal parafascicular port-based resection of cavernomas in deep or eloquent white matter was used with good outcomes.

This approach was pioneered by Dr. Patrick Kelly with a system that used a dilator and a $2-\mathrm{cm}$ or $3-\mathrm{cm}$ tubular retractor for tumor resection with the operating microscope. ${ }^{15,23}$ Later, Nishara and colleagues used an endoscope with a sheath for intracerebral hematoma evacuation. ${ }^{24}$ Further refinements have been made with varying port dimensions and shapes, integration with real-time navigation, and a whole spectrum of optics, including operating microscopes, endoscopes, exoscopes, and ultra-

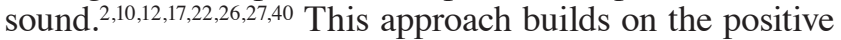
aspects of prior techniques and applies them to cavernoma resection. The basic tenants include image interpretation and trajectory planning, intraoperative navigation, cortical cannulation and subcortical space access, optics and then resection. ${ }^{32}$

\section{Image Interpretation}

Image interpretation is vital and is the foundation of subcortical surgery. Preoperative fMRI and DTI sequences allow the surgeon to reconstruct the important fiber tracts to plan the trajectory. In both cases the fMRI and DTI sequencing identified the motor fibers, which were the primary concern, and a surgical plan avoiding them was created (Figs. 1, 2, and 5). In Case 1 the trajectory
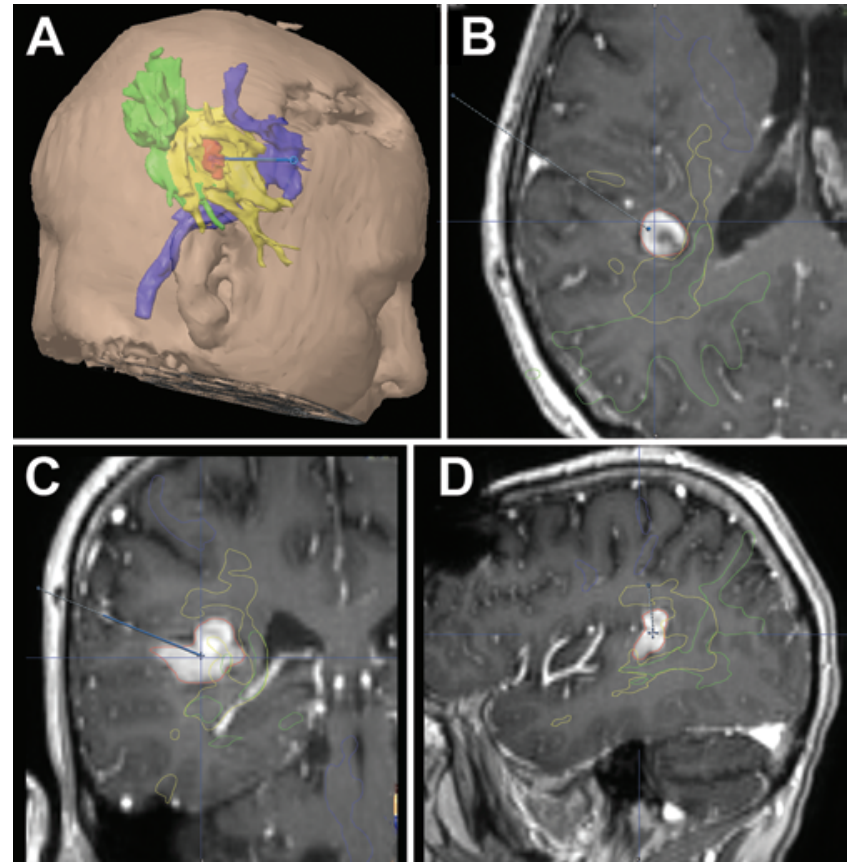

FIG. 5. Case 2. DTI fiber tract reconstructions, 3D view (A) and axial (B), coronal (C), and sagittal (D) fused to a T1-weighted MR image. The corticospinal tract is blue, optic radiations are green, arcuate and superior longitudinal fasciculus are yellow, and cavernoma is red. The blue line shows the surgical corridor.

was very anterior and medial to prevent injury to the corticospinal tract, as the motor fibers wrapped around the anterior and lateral surface of the cavernoma. The tract continued along the inferior surface of the cavernoma, so we had to be cognizant not to go too deep. When planning a trajectory for corridor surgery, one should approach the fiber tracts in a parafscicular rather than transfascicular path to minimize injury.

\section{Cortical Cannulation and Subcortical Space Access}

Entry to the subcortical space is made through the base of a sulcus rather than the crest of a gyrus. This allows for the shortest possible path to the target and less damage to the brain. A draining vein may require adjustment of the plan; however, often times the resolution of navigated MRI is sufficient to identify these preoperatively. The obturator tip is designed to be inserted without the need for a corticectomy and to dissect the tracts atraumatically. As the obturator is inserted under real-time navigation, the assistant irrigates around the edges to decrease friction. Upon reaching the target the obturator is removed, leaving the translucent sheath in place, which provides uniformly distributed retraction. The sheath can be secured and serves to protect tracts during the procedure. The port device is a valuable tool with indications beyond cavernoma resection in subcortical surgery. The cavernomas in both cases could have been resected through traditional microsurgical approaches. The first case would require a larger exposure, more dissection, and more time to create the necessary conical cavity down to the pathology. The advantage of the port in the second case is not as great, 


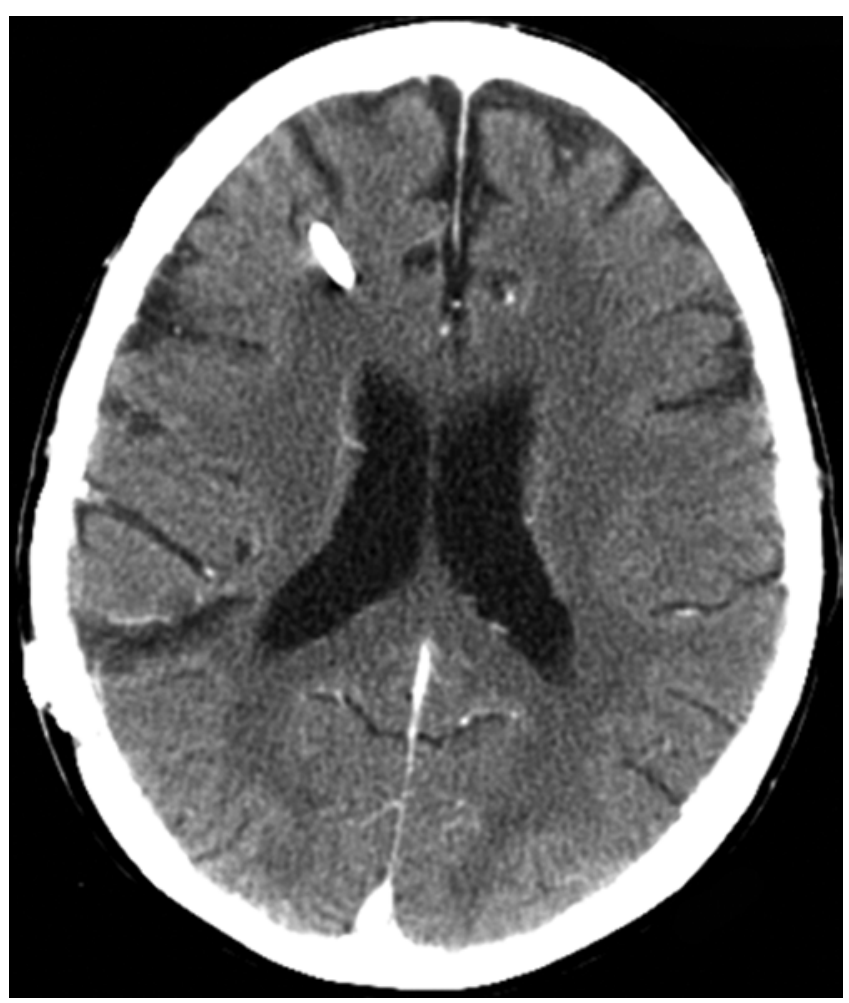

FIG. 6. Case 2. Postoperative postcontrast head CT scan showing no residual cavernoma.

given the shorter distance to the cortical surface. We feel there is still value in that the port provides evenly distributed retraction with uniform exposure. Additionally, the port protects the surrounding fascicles from inadvertent damage while instruments transition to the pathology. Ultimately the approach method will depend on the operating surgeon's experience, skill, and preference.

\section{Intraoperative Navigation}

Intraoperative navigation is critical for the initial access and the procedure. In Case 1 the right corticospinal tract was at the edge of the hematoma cavity on the lateral, anterior, and inferior aspects. The second case was a little more forgiving, but the corticospinal tract was still less than $1 \mathrm{~cm}$ from the area to be resected. Intraoperative navigation was used during both procedures to help identify the edges of resection and proximity to critical structures. The navigation also aids in the wanding maneuver, where the distal portion of the sheath can be moved to expose the edges of larger targets to achieve a complete resection.

\section{Optics}

Advances is neurosurgery have been made as technology in illumination and optics has evolved. We use an exoscope rather than the operating microscope or endoscope. The port has an inside diameter of $13.5 \mathrm{~mm}$; a minimum of $2 \mathrm{~cm}$ is needed for visualization with the microscope. ${ }^{22}$ The endoscope uses valuable space with the tube, limiting dexterity. The exoscope is fixed with a robotic arm positioned at a distance from the port as dictated by the surgeon's preference. The lighting is adequate to illuminate the field, and we have not noted any difficulties with reflections from the wall of the port. The robotic arm also stabilizes the picture and allows bimanual technique. Most neurosurgeons are familiar with the 3D view afforded by a microscope. The exoscope provides a 2D picture, and there is a bit of a learning curve involved that is easily overcome. We recommend practicing with the exoscope in the laboratory before making it a part of clinical practice.

\section{Resection}

Resection through the port is aided by the ability to use both hands, and the walls afford protection to the tracts as instruments are inserted or removed. The sheath is large enough to accommodate standard microneurosurgical instruments, bipolar cautery, and suction. The NICO Myriad system is a valuable device that makes resection through the sheath possible. The device tip is blunt with a side-cutter and connects to a sterile aspiration system. The shaft is malleable and can be bent cautiously to a degree to move the operator's hand from the field of view. The handle is also short enough that it fits between the tip of the exoscope and the field. It works well for resection of soft tissue; firmer tissue presents a difficulty and limits the overall application of the port technology, as in the case of a firm intraventricular meningioma. Wanding the distal end of the port may be helpful in some instances. However, we have found that in most cases, including hematoma evacuation, that as tissue or hematoma is resected the cavity tends to collapse upon itself to a degree, bringing additional pathology into the field of view.

Performing these procedures in an awake fashion with continuous neurological examination whenever possible increases the safety. Great care must be taken to properly register the navigation devices appropriately and monitor for deviations throughout the procedure. Brain shift during the procedure from large openings or drainage of cerebrospinal fluid can render navigation systems inaccurate. $.13,33$ This method allows for a small craniotomy, which helps to minimize shift, increasing the reliability of the navigation. ${ }^{13,33}$

\section{Conclusions}

The transulcal parafascicular minimally invasive approach relies on image interpretation and trajectory planning, intraoperative navigation, cortical cannulation and subcortical space access, high-quality optics, and resection as key elements to minimize exposure and retraction and maximize tissue preservation. We applied this approach to 2 patients with cavernomas in eloquent subcortical white matter and the thalamus with good outcomes.

\section{References}

1. Awad IA, Robinson JR Jr, Mohanty S, Estes ML: Mixed vascular malformations of the brain: clinical and pathogenetic considerations. Neurosurgery 33:179-188, 1993

2. Barlas O, Karadereler S: Stereotactically guided microsurgical removal of colloid cysts. Acta Neurochir (Wien) 146:1199-1204, 2004 
3. Bertalanffy H, Benes L, Miyazawa T, Alberti O, Siegel AM, Sure U: Cerebral cavernomas in the adult. Review of the literature and analysis of 72 surgically treated patients. Neurosurg Rev 25:1-55, 2002

4. Boukobza M, Enjolras O, Guichard JP, Gelbert F, Herbreteau $\mathrm{D}$, Reizine D, et al: Cerebral developmental venous anomalies associated with head and neck venous malformations. AJNR Am J Neuroradiol 17:987-994, 1996

5. Chang EF, Gabriel RA, Potts MB, Berger MS, Lawton MT: Supratentorial cavernous malformations in eloquent and deep locations: surgical approaches and outcomes. Clinical article. J Neurosurg 114:814-827, 2011

6. Chi JH, Lawton MT: Posterior interhemispheric approach: surgical technique, application to vascular lesions, and benefits of gravity retraction. Neurosurgery 59 (1 Suppl 1):ONS41-ONS49, 2006

7. Decker DA, Perry A, Yachnis AT: Vascular and ischemic disorders, in Perry A, Brat DJ (eds): Practical Surgical Neuropathology: A Diagnostic Approach. Philadelphia: Churchill Livingstone, 2010

8. Dorward NL, Alberti O, Palmer JD, Kitchen ND, Thomas DGT: Accuracy of true frameless stereotaxy: in vivo measurement and laboratory phantom studies. Technical note. J Neurosurg 90:160-168, 1999

9. Fernandez-Miranda JC, Engh JA, Pathak SK, Madhok R, Boada FE, Schneider W, et al: High-definition fiber tracking guidance for intraparenchymal endoscopic port surgery. J Neurosurg 113:990-999, 2010

10. Fiorella D, Gutman F, Woo H, Arthur A, Aranguren R, Davis R: Minimally invasive evacuation of parenchymal and ventricular hemorrhage using the Apollo system with simultaneous neuronavigation, neuroendoscopy and active monitoring with cone beam CT. J Neurointerv Surg 7:752-757, 2015

11. Gross BA, Batjer HH, Awad IA, Bendok BR: Cavernous malformations of the basal ganglia and thalamus. Neurosurgery 65:7-19, 2009

12. Harris AE, Hadjipanayis CG, Lunsford LD, Lunsford AK, Kassam AB: Microsurgical removal of intraventricular lesions using endoscopic visualization and stereotactic guidance. Neurosurgery 62 (Suppl 2):622-629, 2008

13. Hill DL, Maurer CR Jr, Maciunas RJ, Barwise JA, Fitzpatrick JM, Wang MY: Measurement of intraoperative brain surface deformation under a craniotomy. Neurosurgery 43:514-528, 1998

14. Kassam AB, Engh JA, Mintz AH, Prevedello DM: Completely endoscopic resection of intraparenchymal brain tumors. J Neurosurg 110:116-123, 2009

15. Kelly PJ, Goerss SJ, Kall BA: The stereotaxic retractor in computer-assisted stereotaxic microsurgery. Technical note. J Neurosurg 69:301-306, 1988

16. Kiliç T, Pamir MN, Küllü S, Eren F, Ozek MM, Black PM: Expression of structural proteins and angiogenic factors in cerebrovascular anomalies. Neurosurgery 46:1179-1192, 2000

17. King WA, Ullman JS, Frazee JG, Post KD, Bergsneider M: Endoscopic resection of colloid cysts: surgical considerations using the rigid endoscope. Neurosurgery 44:1103-1111, 1999

18. Kuo LT, Chen CM, Li CH, Tsai JC, Chiu HC, Liu LC, et al: Early endoscope-assisted hematoma evacuation in patients with supratentorial intracerebral hemorrhage: case selection, surgical technique, and long-term results. Neurosurg Focus 30(4):E9, 2011

19. Lanzino G, Wanebo JE, Spetzler RF: Contralateral interhemispheric resection of thalamic cavernous malformations with frameless stereotaxy. Oper Tech Neurosurg 5:191, 2002

20. Lawton MT, Golfinos JG, Spetzler RF: The contralateral transcallosal approach: experience with 32 patients. Neurosurgery 39:729-735, 1996

21. Li D, Zhang J, Hao S, Tang J, Xiao X, Wu Z, et al: Surgical treatment and long-term outcomes of thalamic cavernous malformations. World Neurosurg 79:704-713, 2013

22. McLaughlin N, Prevedello DM, Engh J, Kelly DF, Kassam $\mathrm{AB}$ : Endoneurosurgical resection of intraventricular and intraparenchymal lesions using the port technique. World Neurosurg 79 (2 Suppl):S18.e1-S18.e8, 2013

23. Morita A, Kelly PJ: Resection of intraventricular tumors via a computer-assisted volumetric stereotactic approach. Neurosurgery 32:920-927, 1993

24. Nishihara T, Teraoka A, Morita A, Ueki K, Takai K, Kirino T: A transparent sheath for endoscopic surgery and its application in surgical evacuation of spontaneous intracerebral hematomas. Technical note. J Neurosurg 92:1053-1055, 2000

25. Ochalski P, Chivukula S, Shin S, Prevedello D, Engh J: Outcomes after endoscopic port surgery for spontaneous intracerebral hematomas. J Neurol Surg A Cent Eur Neurosurg 75:195-206, 2014

26. Ochalski PG, Fernandez-Miranda JC, Prevedello DM, Pollack IF, Engh JA: Endoscopic port surgery for resection of lesions of the cerebellar peduncles: technical note. Neurosurgery 68:1444-1451, 2011

27. Ogura K, Tachibana E, Aoshima C, Sumitomo M: New microsurgical technique for intraparenchymal lesions of the brain: transcylinder approach. Acta Neurochir (Wien) 148:779-785, 2006

28. Otani N, Fujioka M, Oracioglu B, Muroi C, Khan N, Roth P, et al: Thalamic cavernous angioma: paraculminar supracerebellar infratentorial transtentorial approach for the safe and complete surgical removal. Acta Neurochir Suppl 103:29-36, 2008

29. Patel AP, Amin-Hanjani S, Ogilvy CS: Surgical management of cavernous malformations of the nervous system, in Quinones-Hinojosa A (ed): Schmidek \& Sweet Operative Neurosurgical Techniques, ed 6. Philadelphia: Saunders Elsevier, 2012, pp 977-993

30. Pozzati E, Acciarri N, Tognetti F, Marliani F, Giangaspero F: Growth, subsequent bleeding, and de novo appearance of cerebral cavernous angiomas. Neurosurgery 38:662-670, 1996

31. Pozzati E, Giuliani G, Nuzzo G, Poppi M: The growth of cerebral cavernous angiomas. Neurosurgery 25:92-97, 1989

32. Ritsma B, Kassam A, Dowlatshahi D, Nguyen T, Stotts G: Minimally invasive subcortical parafascicular transsulcal access for clot evacuation (Mi SPACE) for intracerebral hemorrhage. Case Rep Neurol Med 2014:102307, 2014

33. Roberts DW, Hartov A, Kennedy FE, Miga MI, Paulsen KD: Intraoperative brain shift and deformation: a quantitative analysis of cortical displacement in 28 cases. Neurosurgery 43:749-760, 1998

34. Rothbart D, Awad IA, Lee J, Kim J, Harbaugh R, Criscuolo GR: Expression of angiogenic factors and structural proteins in central nervous system vascular malformations. Neurosurgery 38:915-925, 1996

35. Scott RM, Barnes P, Kupsky W, Adelman LS: Cavernous angiomas of the central nervous system in children. $\mathbf{J}$ Neurosurg 76:38-46, 1992

36. Simard JM, Garcia-Bengochea F, Ballinger WE Jr, Mickle JP, Quisling RG: Cavernous angioma: a review of 126 collected and 12 new clinical cases. Neurosurgery 18:162-172, 1986

37. Steiger HJ, Markwalder TM, Reulen HJ: Clinicopathological relations of cerebral cavernous angiomas: observations in eleven cases. Neurosurgery 21:879-884, 1987

38. Steinberg GK, Chang SD, Gewirtz RJ, Lopez JR: Microsurgical resection of brainstem, thalamic, and basal 
ganglia angiographically occult vascular malformations. Neurosurgery 46:260-271, 2000

39. Turner RD, Vargas J, Turk AS, Chaudry MI, Spiotta AM: Novel device and technique for minimally invasive intracerebral hematoma evacuation in the same setting of a ruptured intracranial aneurysm: combined treatment in the neurointerventional angiography suite. Neurosurgery 11 (Suppl 2):43-51, 2015

40. Waran V, Vairavan N, Sia SF, Abdullah B: A new expandable cannula system for endoscopic evacuation of intraparenchymal hemorrhages. J Neurosurg 111:1127-1130, 2009

41. Wilms G, Bleus E, Demaerel P, Marchal G, Plets C, Goffin J, et al: Simultaneous occurrence of developmental venous anomalies and cavernous angiomas. AJNR Am J Neuroradiol 15:1247-1257, 1994

42. Zaidi HA, Chowdhry SA, Nakaji P, Abla AA, Spetzler RF: Contralateral interhemispheric approach to deep-seated cavernous malformations: surgical considerations and clinical outcomes in 31 consecutive cases. Neurosurgery 75:80-86, 2014

\section{Disclosures}

The authors report no conflict of interest concerning the materials or methods used in this study or the findings specified in this paper.

\section{Author Contributions}

Conception and design: Britz, Scranton. Acquisition of data: Scranton, Fung. Analysis and interpretation of data: all authors. Drafting the article: all authors. Critically revising the article: all authors. Reviewed submitted version of manuscript: all authors. Approved the final version of the manuscript on behalf of all authors: Britz. Administrative/technical/material support: all authors.

\section{Correspondence}

Gavin W. Britz, Department of Neurological Surgery, Houston Methodist Neurological Institute, Scurlock Tower, Ste. 900, 6560 Fannin St., Houston, TX 77030. email: gbritz@houstonmethodist. org. 